\title{
Perineal injuries and birth positions among 2992 women with a low risk pregnancy who opted for a homebirth
}

\author{
Malin Edqvist ${ }^{1}$, Ellen Blix ${ }^{2^{*}}$ (D, Hanne K. Hegaard ${ }^{3}$, Olöf Ásta Ólafsdottir ${ }^{4}$, Ingegerd Hildingsson ${ }^{5,6}$, Karen Ingversen ${ }^{7}$, \\ Margareta Mollberg ${ }^{1}$ and Helena Lindgren ${ }^{1,8}$
}

\begin{abstract}
Background: Whether certain birth positions are associated with perineal injuries and severe perineal trauma (SPT) is still unclear. The objective of this study was to describe the prevalence of perineal injuries of different severity in a low-risk population of women who planned to give birth at home and to compare the prevalence of perineal injuries, SPT and episiotomy in different birth positions in four Nordic countries.

Methods: A population-based prospective cohort study of planned home births in four Nordic countries. To assess medical outcomes a questionnaire completed after birth by the attending midwife was used. Descriptive statistics, bivariate analysis and logistic regression were used to analyze the data.

Results: Two thousand nine hundred ninety-two women with planned home births, who birthed spontaneously at home or after transfer to hospital, between 2008 and 2013 were included. The prevalence of SPT was $0.7 \%$ and the prevalence of episiotomy was $1.0 \%$. There were differences between the countries regarding all maternal characteristics. No association between flexible sacrum positions and sutured perineal injuries was found (OR 1.02; $95 \% \mathrm{Cl} 0.86-1.21)$ or SPT (OR 0.68; Cl 95 \% 0.26-1.79). Flexible sacrum positions were associated with fewer episiotomies (OR 0.20; Cl 95 \% 0.10-0.54).

Conclusion: A low prevalence of SPT and episiotomy was found among women opting for a home birth in four Nordic countries. Women used a variety of birth positions and a majority gave birth in flexible sacrum positions. No associations were found between flexible sacrum positions and SPT. Flexible sacrum positions were associated with fewer episiotomies.
\end{abstract}

Keywords: Home birth, Birth positions, Severe perineal trauma, Perineal injuries, Episiotomy, Waterbirth

\section{Background}

Perineal injuries and severe perineal trauma involving the anal sphincter complex (SPT) are associated with shortand long-term morbidity, such as perineal pain [1, 2], dyspareunia [2,3] and anal incontinence [4]. Both short- and long-term symptoms have an impact on women's daily lives [5] and on women's quality of life for those with persistent defects [6]. The prevalence of perineal injuries of all types is reported to be $77-86 \%[7,8]$ of which $60 \%$ need to be

\footnotetext{
* Correspondence: ellen.blix@hioa.no

${ }^{2}$ Research Group: Maternal, Reproductive and Children's Health, Faculty of Health Sciences, Oslo and Akershus University College of Applied Sciences, Oslo, Norway

Full list of author information is available at the end of the article
}

sutured [8]. The incidence of SPT in the Nordic countries (in this article 'Nordic countries' refers to Norway, Sweden, Denmark and Iceland) varies from $2.3 \%$ in Norway to $4.2 \%$ in Denmark [9-11] whereas there is no national data available regarding the prevalence of less severe injuries.

Known risk factors for perineal trauma, including SPT are primiparity [12, 13], high birth weight [12] and occiput posterior presentation [14]. Obstetrical factors associated with SPT are a prolonged second stage [12, 15], instrumental delivery [16], episiotomy [17], poor visualization of the perineum [16], fundal pressure [12], the lithotomy position [18] and oxytocin augmentation [19]. Few studies have assessed risk factors for less severe perineal trauma such as second degree tears but the risk factors appears to 
be similar [20]. Home births have been associated with fewer perineal injuries and SPT compared to hospital births [21-23].

Women who choose home birth are a selected and highly motivated population. Generally they are multiparous, are older, and tend to have a higher socioeconomic status [24]. Fewer are smokers and overweight, which can be viewed as indicators of health [25]. The prevalence of planned home birth varies in the Nordic countries. In Sweden and Norway it is $0.06 \%$ and $0.019 \%$ respectively, while home birth is more common in Denmark and Iceland with 1.5-1.8 \% [26]. It is not known whether the observed benefit of opting for a home birth with regard to SPT and perineal injuries is due to differences in midwifery practice, the selected population of women or other factors, such as birth position. Midwifery care measures at home to prevent perineal injuries include getting to know the woman before the onset of labor, following the physiological process of birth and letting her choose the position for birth [27]. Furthermore some of the obstetrical risk factors of SPT are not present in the home birth setting, such as instrumental delivery, the lithotomy position for birth, and oxytocin augmentation since the woman will be transferred to hospital in the event of an emergency or slow progress of labor. Waterbirth on the other hand is common in this setting [28]; in some studies it is associated with SPT and perineal injuries [23, 29] but not in others [30].

There is still controversy around whether upright or recumbent birth positions are beneficial or harmful with regard to SPT as well as less severe perineal injuries. Giving birth in the lateral and all-fours position has been associated with a higher prevalence of intact perineum [31-33] but this is not found in the meta-analysis by Gupta et al. [34]. Upright birth positions occur more often within certain birth settings, such as birth centers and at home [28]. Upright birth positions in Western obstetrics may be defined as positions in which a line connecting the center of a woman's third and fifth vertebrae is more vertical than horizontal [34, 35]. According to this definition sitting, squatting, the birth-seat, kneeling and standing are defined as upright positions, whereas lateral and all-fours, semi-recumbent and the lithotomy position are considered supine positions [34], although they are different and may facilitate or hinder physiological birth.

Another possible definition is to classify birth positions in which the body weight is on or off the sacrum. Positions that take the weight off the sacrum and allow the pelvic outlet to expand might be favorable to facilitating spontaneous birth [36]. Birth positions that take the weight off the sacrum and could be categorized as flexible sacrum positions are kneeling, standing, all-fours, lateral position, squatting and giving birth on the birth seat. On the other hand all the positions where the woman is sitting or lying on her back, such as the supine and the semi-recumbent position put weight on the sacrum and could be categorized as non-flexible sacrum positions. The evidence as to the impact of upright birth and flexible sacrum positions on perineal outcomes remains inconclusive [36] and has to our knowledge not been tested in the home birth setting. Since home births are seldom recorded in the registers in the Nordic countries, the prevalence of perineal injuries, SPT, episiotomy and birth positions for women opting for a home birth is not known.

The objective of this study is to describe the prevalence of perineal injuries of different severity in a lowrisk population of women who planned to give birth at home in four Nordic countries and to compare the prevalence of perineal injuries, SPT and episiotomy in flexible and non-flexible birth positions.

\section{Method \\ Design and study sample}

This is a prospective cohort study collecting data from planned home births in Norway, Denmark, Sweden and Iceland between 2008 and 2013. All midwives attending home births were asked to recruit their clients to the study. The women were given information about the study during pregnancy, and signed a form agreeing to participate. The method and data collection has been described previously by Blix et al. [37]

\section{Data collection}

The data collection lasted from January $1^{\text {st }} 2008$ to December $31^{\text {st }} 2012$ in Norway, in Sweden from January $1^{\text {st }} 2009$ to December $31^{\text {st }} 2013$, in Denmark from March $1^{\text {st }} 2010$ to May $15^{\text {th }} 2013$ and in Iceland from January $1^{\text {st }}$ 2010 to December $31^{\text {st }} 2013$.

The questionnaire included information about women's background characteristics (country of residence, age, parity, marital status, Body Mass Index, tobacco use) (Table 1) and was completed by the attending midwife 1 week after the birth. The questionnaire also contained information about place of birth (home, during transfer, hospital) and birth outcome related to the woman [37]. All births that were planned to take place at home and started at home are included in the cohort irrespective of where the baby actually was born, at home or after transfer to the hospital. Birth positions were assessed according to type of position at the moment when the baby was born. Eight different positions were predefined. The positions that aim at expanding the pelvic outlet and taking weight off the sacrum are defined as flexible sacrum positions in this study. Birth positions were dichotomized into two groups: flexible or non-flexible sacrum positions. Positions that take the weight off the sacrum are: kneeling, standing, all- 
Table 1 Socio-demographic background

\begin{tabular}{|c|c|c|c|c|c|c|}
\hline & Total & Norway & Sweden & Denmark & Iceland & Chi'test \\
\hline & $N=2992$ & $N=468$ & $N=438$ & $N=1799$ & $N=287$ & $p$-value \\
\hline & $\mathrm{n}(\%)$ & n (\%) & n (\%) & n (\%) & n (\%) & \\
\hline Age groups & & & & & & $<0.001$ \\
\hline$<25$ years & $202(6.8)$ & $26(5.6)$ & $24(5.5)$ & $119(6.6)$ & $33(11.5)$ & \\
\hline 25-34 years & $1923(64.3)$ & $295(63.0)$ & $234(53.4)$ & $1188(66.0)$ & $206(72.0)$ & \\
\hline$>35$ years & $850(28.4)$ & $145(31.0)$ & $177(40.4)$ & $481(26.7)$ & $47(16.4)$ & \\
\hline Missing & $17(0.6)$ & $2(0.4)$ & $3(0.7)$ & $11(0.6)$ & $1(0.3)$ & \\
\hline Marital status & & & & & & $<0.001$ \\
\hline Married/cohabit & 2918 (97.5) & $449(95.7)$ & 407 (92.9) & 1779 (98.9) & $284(99.0)$ & \\
\hline Not married/cohabit & $51(1.7)$ & $17(3.6)$ & $13(3.0)$ & $20(1.1)$ & $1(0.3)$ & \\
\hline Missing & $23(0.8)$ & $3(0.6)$ & $18(4.1)$ & 0 & $2(0.7)$ & \\
\hline Tobacco use & & & & & & $<0.001$ \\
\hline Yes & $198(6.6)$ & $16(3.4)$ & $5(1.1)$ & $167(9.3)$ & $10(3.5)$ & \\
\hline No & 2735 (91.4) & $450(96.2)$ & $425(97.0)$ & $1587(88.2)$ & $273(95.1)$ & \\
\hline Missing & $59(2.0)$ & $2(0.4)$ & $8(1.8)$ & $45(2.5)$ & $4(1.4)$ & \\
\hline Number of children & & & & & & 0.004 \\
\hline First baby & $524(17.5)$ & $80(17.1)$ & $70(16.0)$ & $313(17.4)$ & $61(21.3)$ & \\
\hline One previous child & $1257(42.0)$ & $175(37.4)$ & $208(47.5)$ & $753(41.9)$ & $121(42.2)$ & \\
\hline Two previous children & $828(27.7)$ & $137(29.3)$ & $113(25.8)$ & $494(27.5)$ & $84(29.3)$ & \\
\hline Three or more previous children & $322(10.8)$ & $74(15.8)$ & $46(10.5)$ & $182(10.1)$ & $20(7.0)$ & \\
\hline Missing & $61(2.0)$ & $2(0.4)$ & $1(0.2)$ & $57(3.2)$ & $1(0.3)$ & \\
\hline \multicolumn{7}{|l|}{ Body Mass Index (BMI), mean (SD) } \\
\hline BMl-groups & & & & & & 0.001 \\
\hline$<18.5$ & $101(3.4)$ & $16(3.4)$ & $16(4.7)$ & $60(3.3)$ & $9(3.1)$ & \\
\hline $18,5-24.9$ & $1943(64.9)$ & $289(61.8)$ & $260(59.4)$ & $1220(67.8)$ & $174(60.6)$ & \\
\hline $25.0-29.9$ & $516(17.2)$ & 87 (18.6) & $51(11.6)$ & $323(18.0)$ & 55 (19.9) & \\
\hline$>30$ & $196(6.6)$ & $25(5.3)$ & $17(3.9)$ & $116(6.4)$ & $38(13.2)$ & \\
\hline Missing & $236(7.9)$ & $51(10.9)$ & $94(21.5)$ & $80(4.4)$ & $11(3.8)$ & \\
\hline
\end{tabular}

fours, squatting, the birth seat and lateral. Positions defined as non-flexible are semi-recumbent, lithotomy and supine positions. Perineal injuries were reported as sutured injury or not, episiotomy and SPT. A non-sutured injury includes no tear at all, small abrasions or minor injuries, which the midwife considered did not require suturing. A variable was created to capture total recorded perineal injuries, where SPT, episiotomy and sutured injuries were included.

\section{Analysis}

Descriptive statistics, $\mathrm{Chi}^{2}$ and ANOVA tests were used to present the background characteristics and compare data between the Nordic countries. The outcome variables were sutured perineal and vaginal injuries, SPT, episiotomies and total posterior trauma. Crude and adjusted odds ratios with a $95 \%$ confidence interval were calculated between the outcome variables and flexible sacrum positions. Potential confounders were adjusted for using logistic regression. The IBM SPSS software package version 22.0 was employed for the data analysis.

\section{Results}

For the purpose of this study, a selected sample of 2992 of the original cohort of 3068 women with a planned home birth was included. A total of 76 women who had a caesarean section or an instrumental delivery after transfer to hospital were excluded. Instrumental deliveries were excluded since they are performed in a supine or recumbent birth position. Of the 2992 women, 2796 (93.4 \%) successfully gave birth at home and 196 (6.6\%) gave birth spontaneously after transfer to the hospital. The most common reason for transfer was slow progress of labor.

Table 1 shows the background characteristics of the 2992 women included in this study. The majority of the 
planned home births in this study occurred in Denmark $(n=1799)$, followed by Norway $(n=468)$, Sweden $(n=$ $438)$ and Iceland $(n=287)$. The mean age for the total sample was 32 years (range 18-47). There were significant differences between the countries regarding all maternal characteristics. The Icelandic mothers were the youngest and the Swedish mothers were the oldest. The highest proportion of planned home births for women expecting their first baby occurred in Iceland (21.7 \%) and in Denmark (18.5\%). Most women irrespective of country were married or cohabiting, did not smoke and were expecting their second baby. Among the multiparous women in the cohort, 140 (4.7\%) women attempted a planned home birth after a caesarean section (VBAC). The vast majority $(85 \%)$ of these planned VBAC home births occurred in Denmark.

The prevalence of SPT was $0.7 \%$ for the total study population, $2.3 \%$ among primiparas and $0.3 \%$ among multiparas (Table 2). The only risk factors for SPT found in this study were primiparity (adj OR 9.90; CI $95 \%$ 3.63-26.98) and birth weight $>4000 \mathrm{~g}$ (adj OR 2.87; CI $95 \%$ 1.07-7.75) (Table 4). The overall prevalence of

Table 2 Birth outcomes

\begin{tabular}{|c|c|c|c|c|}
\hline & Total & Primiparas & Multiparas ${ }^{a}$ & Missing \\
\hline & $N=2992$ & $N=524$ & $N=2422$ & $N=46(1.5)$ \\
\hline & n (\%) & n (\%) & n (\%) & \\
\hline \multicolumn{5}{|l|}{ Birth weight } \\
\hline$<2999 \mathrm{~g}$ & $134(4.5)$ & $44(8.4)$ & $88(3.6)$ & \\
\hline 3000-3999 g & $2029(67.8)$ & $392(74.8)$ & 1609 (66.4) & \\
\hline $4000-4499 \mathrm{~g}$ & $607(20.3)$ & $55(10.5)$ & $541(22.3)$ & \\
\hline$>4500 \mathrm{~g}$ & $143(4.8)$ & $15(2.9)$ & $127(5.2)$ & \\
\hline Missing & $79(2.6)$ & $18(3.4)$ & $57(2.4)$ & \\
\hline \multicolumn{5}{|l|}{ Sutured injury } \\
\hline Yes & $1242(41.5)$ & $319(60.9)$ & $891(36.8)$ & \\
\hline No & $1709(57.1)$ & $196(37.4)$ & 1499 (61.9) & \\
\hline Missing & $41(1.4)$ & $9(1.7)$ & $32(1.3)$ & \\
\hline \multicolumn{5}{|l|}{ OASIS } \\
\hline Yes & $21(0.7)$ & $12(2.3)$ & $7(0.3)$ & \\
\hline No & 2937 (98.2) & $501(95.6)$ & $2392(98.8)$ & \\
\hline Missing & $34(1.1)$ & $11(2.1)$ & $23(0.9)$ & \\
\hline \multicolumn{5}{|l|}{ Episiotomy } \\
\hline Yes & $31(1.0)$ & $23(4.4)$ & $7(0.3)$ & \\
\hline No & $2926(97.8)$ & $493(94.1)$ & $2388(98.6)$ & \\
\hline Missing & $35(1.2)$ & $8(1.5)$ & $27(1.1)$ & \\
\hline \multicolumn{5}{|c|}{ Total perineal injury } \\
\hline Yes & $1276(42.6)$ & $342(65.3)$ & $899(37.1)$ & \\
\hline No & 1669 (55.8) & $174(33.2)$ & $1484(61.3)$ & \\
\hline Missing & $47(1.6)$ & $8(1.5)$ & $39(1.6)$ & \\
\hline
\end{tabular}

${ }^{\mathrm{a}} 141$ women with one previous $\mathrm{CS}, 3$ women with 2 previous CS sutured injuries was $41.5 \%$ (Table 2). When stratifying for parity, $60.9 \%$ of the primiparous women had injuries considered as needing sutures and so did $36.8 \%$ of the multiparous women. The prevalence of episiotomy was $1.0 \%$. The women who were transferred to hospital were more likely to have an episiotomy (OR 3.98; CI $95 \%$ 1.72-9.22) (Table 4).

Women gave birth in a variety of positions (Table 3 ). The majority $(65.2 \%)$ used flexible sacrum positions. Kneeling was the most frequently used birth position of the flexible sacrum positions regardless of parity (24.6\%). However for primiparous women semirecumbent, which is considered as a non-flexible sacrum position was the most common position for birth (29.6\%), followed by kneeling (19.1\%) (Table 3). The prevalence of waterbirth was $31.8 \%$ (Table 2) but varied in the four countries. Almost half of the Icelandic women in this cohort gave birth in water (48.1\%) compared to only $6.6 \%$ in Sweden. No association between flexible sacrum positions and sutured injuries was found (OR 1.02; CI $95 \%$ 0.86-1.21) or between flexible sacrum positions and SPT (OR 0.68; CI $95 \%$ 0.26-1.79). Flexible sacrum positions were associated with fewer episiotomies after adjusting for potential confounders (primiparity, birth weight, transfer before birth and waterbirth) (OR 0.20; CI $95 \%$ 0.10-0.54) (Table 4).

Table 3 Birth positions, waterbirth and flexible sacrum positions stratified by parity

\begin{tabular}{lllll}
\hline \multirow{2}{*}{ Total } & Total & Primiparas & Multiparas & Missing \\
& $\mathrm{N}=2992$ & $\mathrm{~N}=524$ & $\mathrm{~N}=2422$ & $\mathrm{~N}=46(1.5)$ \\
$\mathrm{n}(\%)$ & $\mathrm{n}(\%)$ & $\mathrm{n}(\%)$ & $\mathrm{n}(\%)$ \\
\hline Birth position & & & & \\
Semi-recumbent & $687(23.0)$ & $155(29.6)$ & $516(21.3)$ & \\
Supine & $238(8.0)$ & $49(9.4)$ & $185(7.6)$ & \\
Lateral & $420(14.0)$ & $64(12.2)$ & $351(14.5)$ & \\
Birth seat/squatting & $251(8.4)$ & $62(11.8)$ & $187(7.7)$ & \\
All-fours & $326(10.9)$ & $45(8.6)$ & $278(11.5)$ & \\
Kneeling & $737(24.6)$ & $100(19.1)$ & $629(26.0)$ & \\
Standing & $216(7.2)$ & $24(4.6)$ & $190(7.8)$ & \\
Missing & $117(3.9)$ & $25(4.8)$ & $86(3.6)$ \\
Flexible sacrum ${ }^{\mathrm{a}}$ & & & \\
Yes & $1950(65.2)$ & $295(56.3)$ & $1635(67.5)$ & \\
No & $925(30.9)$ & $204(38.9)$ & $701(28.9)$ & \\
Missing & $117(3.9)$ & $25(4.8)$ & $86(3.6)$ \\
Waterbirth & & & \\
Yes & $952(31.8)$ & $186(35.5)$ & $755(31.2)$ \\
No & $2031(67.9)$ & $336(64.1)$ & $1660(68.5)$ \\
Missing & $9(0.3)$ & $2(0.4)$ & $7(0.3)$ \\
\hline
\end{tabular}

${ }^{a}$ kneeling, all-fours, standing, squatting, birth seat, lateral 
Table 4 Risk factors for different types of perineal trauma

\begin{tabular}{|c|c|c|c|c|c|c|c|c|}
\hline & \multicolumn{2}{|l|}{ OASIS } & \multicolumn{2}{|l|}{ Episiotomy } & \multicolumn{2}{|l|}{ Sutured injury } & \multicolumn{2}{|c|}{ Total perineal trauma } \\
\hline & Crude OR & Adjusted OR & Crude OR & Adjusted OR & Crude OR & Adjusted OR & Crude OR & Adjusted OR \\
\hline Primiparity $^{d}$ & $8.19(3.21-20.89)$ & $9.90(3.63-26.98)^{c}$ & $15.92(6.79-37.30)$ & $10.84(4.28-27.45)^{c}$ & $2.74(2.25-3.33)$ & $3.07(2.48-3.81)^{c}$ & $3.25(2.66-3.97)$ & $3.60(2.89-4.49)^{c}$ \\
\hline Birthweight $>4000 \mathrm{~g}^{\mathrm{d}}$ & $1.93(0.79-4.75)$ & $2.87(1.07-7.75)^{\mathrm{a}}$ & $0.75(0.31-1.85)$ & $1.58(0.59-4.18)$ & $1.30(1.10-1.54)$ & $1.48(1.24-1.77)^{c}$ & $1.32(1.11-1.56)$ & $1.53(1.28-1.83)^{\mathrm{c}}$ \\
\hline Transfer before birth & $2.42(0.71-8.30)$ & $0.46(0.06-3.59)$ & $11.02(5.31-22.84)$ & $3.98(1.72-9.22)^{\mathrm{b}}$ & $1.33(0.99-1.79)$ & $0.91(0.65-1.28)$ & $1.60(1.19-2.15)$ & $1.01(0.71-1.42)$ \\
\hline Country & $1.19(0.70-2.03)$ & $1.07(0.60-1.90)$ & $1.28(0.82-2.01)$ & $1.27(0.78-2.09)$ & $1.45(1.32-1.58)$ & $1.42(1.29-1.56)^{c}$ & $1.47(1.34-1.61)$ & $1.44(1.31-1.59)^{\mathrm{c}}$ \\
\hline Flexible sacrum positions ${ }^{\mathrm{e}}$ & $0.71(0.29-1.75)$ & $0.68(0.26-1.79)$ & $0.20(0.10-0.44)$ & $0.20(0.10-0.54)^{b}$ & $0.89(0.76-1.04)$ & $1.02(0.86-1.21)$ & $0.84(0.71-0.98)$ & $0.96(0.81-1.14)$ \\
\hline Waterbirth & $1.30(0.54-3.16)$ & $0.99(0.36-2.73)$ & $0.41(0.16-1.06)$ & $0.36(0.13-1.03)$ & $1.19(1.02-1.39)$ & $1.01(0.85-1.20)$ & $1.19(1.02-1.39)$ & $1.01(0.85-1.21)$ \\
\hline
\end{tabular}

$\mathrm{a}<0.05$

$c<0.001$
$c 001$

dadjusted for birthweight, transfer, flexile sacrum positions, waterbirth, country

eadjusted for parity, birthweight, transfer, waterbirth 


\section{Discussion}

The major finding of this study is a low prevalence of SPT and episiotomy which did not differ between the countries. The women in this cohort used a variety of birth positions and one third of them gave birth in water. No association was found between flexible sacrum positions and SPT or sutured injuries. Episiotomy was associated with giving birth in a non-flexible sacrum position.

The prevalence of SPT and episiotomy in this study is in line with previous research $[21,24,38]$ and adds to the growing body of evidence regarding positive maternal outcomes and low levels of intervention for women with low risk choosing to give birth outside the hospital. Furthermore, the prevalence of SPT and episiotomy in this study did not differ between the countries, which is interesting considering the observed differences between the Nordic countries (2.3 to $4.2 \%$ ) [9-11]. Stating what prevalence of SPT should be considered to indicate good quality of care is problematic and has been discussed [39]. A low prevalence of SPT could be due to successful interventions during the second stage. On the other hand when midwives and obstetricians focus on assessment and classifying perineal injuries, the detection rate of SPT often increases [39, 40]. A prevalence between 1.0 and $3.9 \%$ has been suggested to be a realistic target in high-risk units [39] but what rate is reasonable in a low-risk setting is not known. A lower prevalence of SPT could be expected in a low-risk setting such as home birth where fewer of the obstetrical interventions associated with SPT are present. Stedenfeldt et al. (2014) have shown that the greatest reduction in sphincter injuries after an educational program for midwives and obstetricians took place among low risk-births (i.e., second child, birth weight $<4000 \mathrm{~g}$ and spontaneous birth with the baby in the occiput anterior position) [41].

The women in this study used a variety of birth positions and the majority used flexible sacrum positions. A recent review of the literature reports physical and psychological benefits for women when they give birth in an upright position of their choice [42] but the position assumed by women during birth is influenced by several complex factors. Upright birth positions occur more often within certain birth settings, such as birth centers and home $[28,29]$. The midwife's preference [43] as well as cultural values may influence the position for birth $[34,42]$. It is not possible in this study to determine whether midwives influenced the position for birth but the variation in positions used suggests that women had the opportunity to choose position themselves. Although the number of SPT in this study was low, with only 21 detected cases, no generalizations can be drawn. However, none of the birth positions used - supine, upright or flexible sacrum positions - was associated with SPT which is in line with meta-analyses of the subject [34]. This indicates that midwives were skilled in attending women in different birth positions and it is also in line with the current evidence suggesting that women should be encouraged to give birth in the position most comfortable for them [34].

Flexible sacrum positions were associated with fewer episiotomies. To our knowledge and according to the midwifery literature $[44,45]$, midwives are taught to perform an episiotomy in the lithotomy or semi-recumbent position. This could imply that this finding is confounded by indication. If a midwife finds it necessary to perform an episiotomy, she will ask the woman to change position from a flexible sacrum position to a non-flexible sacrum position (semi-recumbent or supine). However, when looking at which birth position women had when the episiotomy was cut, 9 (30.0\%) of the 30 episiotomies were performed in a position other than the semi-recumbent or supine: 7 in the lateral position, 1 in squatting and 1 in the all-fours position. Five of the episiotomies were performed in water.

One limitation of this study is the lack of information regarding midwifery practices during the second stage to prevent perineal injuries, as well as midwives' experience and training in assessing and suturing perineal injuries. There is evidence that perineal injuries are often misclassified [46] by both midwives and obstetricians. A second examiner and educational workshops have been shown to improve diagnosis and the appropriate classification of perineal trauma $[46,47]$. Information regarding whether a rectal examination has been performed would be of value in further studies.

Another limitation is that midwives in four different countries entered the data. However, using the same protocol limits the classification bias. Midwives who assist women at home births are usually employed within the health care system and are used to recording this type of data, which is similar to the data entered in hospital records. The strength of this study is that the majority of women opting for a home birth and all the midwives assisting with home births on a regular basis in Norway, Sweden, Denmark and Iceland were identified and agreed to participate in this study. According to Blix et al. [48] the original cohort of 3068 women is suggested to cover $80-90 \%$ of the planned home births in the four Nordic countries.

It is important to evaluate perineal outcome in relation to birth setting, since perineal injuries are associated with short- and long-term morbidity for women [49]. Home births in Norway, Sweden, Denmark and Iceland are not always registered and it is not possible to access the data specific to this study from the medical birth registers. The population studied consists of healthy women, giving birth without many of the interventions 
associated with modern obstetrics. Further studies are needed to assess long-term consequences of childbirth, such as urinary incontinence, dyspareunia, anal incontinence and the prevalence of prolapse in women giving birth at home. It would be of interest to study the impact of physiological birth on the pelvic floor in this group of women since they receive low levels of obstetric interventions.

\section{Conclusion}

A low prevalence of SPT and episiotomy was found among women opting for a home birth in four Nordic countries. Women used a variety of birth positions and a majority gave birth in flexible sacrum positions. No associations were found between flexible sacrum position and SPT. Further studies are needed to assess the longterm consequences related to perineal injuries for women giving birth at home.

\section{Acknowledgements}

The authors want to thank all the women who participated in this study, and Anette S. Huitfeldt and Ásrún Ösp Jónsdottir for collecting data in Norway and Iceland.

Avaliability of the dataset: Please contact the corresponding author.

\section{Funding}

The study was funded by the Northern Norway Regional Health Authority, the Swedish Council for Working Life and Social Research, the Danish Association of Midwives' Research Fund, Aase and Ejnar Danielsen's Fund, Denmark, the Icelandic Association of Midwives' Research Fund and Oslo and Akershus University College for Applied Sciences, Norway.

\section{Authors' contribution}

$H L, E B$ and ÓÁÓ initiated and designed the study together with Hanne Kjærgaard, who passed away in December 2013. Kl, HL, EB and ÓÁÓ carried out the data collection. ME analyzed the data and wrote the manuscript. ME, $\mathrm{HL}, \mathrm{H}, E B, H K H, O ́ A ́ O ́, M M$ and $\mathrm{KI}$ participated in interpretation of results and participated in the writing process. ME, HL, IH, EB, HKH, ÓÁÓ, MM and KI read and approved the final manuscript.

\section{Competing interests}

The authors declare that they have no competing interests.

\section{Ethical approval}

The study was approved separately in each of the participating countries, by the Regional Committee for Medical and Health Research Ethics (REC North) (200704605-5) in Norway, by the Regional Committee at Karolinska Institutet (2009/147-31) in Sweden, by The Capital Region Committee on Health Research Ethics (H-3-2014-FSP71) in Denmark, and by The National Bioethics Committee (No. 11-031) in Iceland. All women participating in this study were given written information and consented to participate. They were informed of the possibility to withdraw their consent at any time without any consequences regarding care during pregnancy, birth and the postnatal period.

\section{Author details}

${ }^{1}$ Institute of Health and Care Sciences, The Sahlgrenska Academy, University of Gothenburg, Arvid Wallgrens backe hus 1, Box (PO) 45740530 Gothenburg, Sweden. ${ }^{2}$ Research Group: Maternal, Reproductive and Children's Health, Faculty of Health Sciences, Oslo and Akershus University College of Applied Sciences, Oslo, Norway. ${ }^{3}$ Research Unit, Women's and Children's Health, Juliane Marie Center for Women, Children and Reproduction, Copenhagen University Hospital, Rigshospitalet, Copenhagen, Denmark. ${ }^{4}$ Department of Midwifery, Faculty of Nursing, University of Iceland, Reykjavík, Iceland. ${ }^{5}$ Department of Nursing, Mid Sweden University, Sundsvall, Sweden. 'Department of Women's and Children's Health, Uppsala University,
Uppsala, Sweden. ${ }^{7}$ Homebirth Association Sealand, Copenhagen, Denmark. ${ }^{8}$ Department of Women's and Children's Health, Karolinska Institute, Stockholm, Sweden

Received: 7 February 2016 Accepted: 23 July 2016

Published online: 29 July 2016

\section{References}

1. Macarthur AJ, Macarthur C. Incidence, severity, and determinants of perineal pain after vaginal delivery: a prospective cohort study. Am J Obstet Gynecol. 2004:191(4):1199-204

2. Schytt $E$, Lindmark $G$, Waldenstrom $U$. Physical symptoms after childbirth: prevalence and associations with self-rated health. BJOG. 2005;112(2):210-7.

3. Rathfisch G, Dikencik BK, Kizilkaya Beji N, Comert N, Tekirdag Al, Kadioglu A. Effects of perineal trauma on postpartum sexual function. J Adv Nurs. 2010; 66(12):2640-9

4. Sultan AH, Kamm MA, Hudson CN, Bartram Cl. Third degree obstetric anal sphincter tears: risk factors and outcome of primary repair. BMJ (Clinical research ed). 1994;308(6933):887-91.

5. Way S. A qualitative study exploring women's personal experiences of their perineum after childbirth: expectations, reality and returning to normality. Midwifery. 2012;28(5):e712-9.

6. Reid AJ, Beggs AD, Sultan AH, Roos AM, Thakar R. Outcome of repair of obstetric anal sphincter injuries after three years. Int J Gynaecol Obstet. 2014;127(1):47-50

7. Albers LL, Sedler KD, Bedrick EJ, Teaf D, Peralta P. Midwifery care measures in the second stage of labor and reduction of genital tract trauma at birth: a randomized trial. J Midwifery Womens Health. 2005;50(5):365-72.

8. McCandlish R, Bowler U, van Asten H, Berridge G, Winter C, Sames L, Garcia J, Renfrew M, Elbourne D. A randomised controlled trial of care of the perineum during second stage of normal labour. $\mathrm{Br} J$ Obstet Gynaecol. 1998;105(12):1262-72.

9. Laine K, Rotvold W, Staff AC. Are obstetric anal sphincter ruptures preventable?- large and consistent rupture rate variations between the Nordic countries and between delivery units in Norway. Acta Obstet Gynecol Scand. 2013;92(1):94-100.

10. National Board of health and Welfare. Graviditeter, förlossningar och nyfödda barn. Medicinska födelseregistret 1973-2014. (National data from the Swedish Birthregister - annual report 1973-2014), vol. 2016. Welfare NBoha; 2015. http://www.socialstyrelsen.se/publikationer2015/2015-12-27

11. Bjarnadottir RG, Smárason AK, Pálsson Gl. Faedingarskráningunni fyrir árid 2013. (Report from the Icelandic Birth Registry for 2013), vol. 2016. National Hospital of Iceland R; 2013. http://www.landspitali.is/library/Sameiginlegarskrar/Gagnasafn/Rit-og-skyrslur/Faedingaskraningar/faedingarskraning_ skyrsla_2013.pdf.

12. de Leeuw JW, Struijk PC, Vierhout ME, Wallenburg HC. Risk factors for third degree perineal ruptures during delivery. BJOG. 2001;108(4):383-7.

13. Elfaghi I, Johansson-Ernste B, Rydhstroem $H$. Rupture of the sphincter ani: the recurrence rate in second delivery. BJOG. 2004;111(12):1361-4.

14. Raisanen SH, Vehvilainen-Julkunen K, Gissler M, Heinonen S. Lateral episiotomy protects primiparous but not multiparous women from obstetric anal sphincter rupture. Acta Obstet Gynecol Scand. 2009;88(12):1365-72.

15. Valsky DV, Lipschuetz M, Bord A, Eldar I, Messing B, Hochner-Celnikier D, Lavy Y, Cohen SM, Yagel S. Fetal head circumference and length of second stage of labor are risk factors for levator ani muscle injury, diagnosed by 3-dimensional transperineal ultrasound in primiparous women. Am J Obstet Gynecol. 2009;201(1):91.e91-97.

16. Samuelsson E, Ladfors L, Wennerholm UB, Gareberg B, Nyberg K, Hagberg $\mathrm{H}$. Anal sphincter tears: prospective study of obstetric risk factors. BJOG. 2000;107(7):926-31.

17. Carroli G, Mignini L. Episiotomy for vaginal birth. The Cochrane database of systematic reviews. 2009;(1):Cd000081.

18. Gottvall $K$, Allebeck $P$, Ekeus $C$. Risk factors for anal sphincter tears: the importance of maternal position at birth. BJOG. 2007;114(10):1266-72.

19. Rygh AB, Skjeldestad FE, Korner H, Eggebo TM. Assessing the association of oxytocin augmentation with obstetric anal sphincter injury in nulliparous women: a population-based, case-control study. BMJ open. 2014:4(7), e004592

20. Samuelsson $E$, Ladfors $L$, Lindblom $B G$, Hagberg $H$. A prospective observational study on tears during vaginal delivery: occurrences and risk factors. Acta Obstet Gynecol Scand. 2002;81(1):44-9. 
21. Lindgren HE, Radestad IJ, Christensson K, Hildingsson IM. Outcome of planned home births compared to hospital births in Sweden between 1992 and 2004. A population-based register study. Acta Obstet Gynecol Scand. 2008;87(7):751-9.

22. Hutton EK, Reitsma AH, Kaufman K. Outcomes associated with planned home and planned hospital births in low-risk women attended by midwives in Ontario, Canada, 2003-2006: a retrospective cohort study. Birth (Berkeley, Calif). 2009;36(3):180-9.

23. McPherson KC, Beggs AD, Sultan AH, Thakar R. Can the risk of obstetric anal sphincter injuries (OASIs) be predicted using a risk-scoring system? BMC research notes. 2014;7:471.

24. Brocklehurst P, Hardy P, Hollowell J, Linsell L, Macfarlane A, McCourt C, Marlow N, Miller A, Newburn M, Petrou S, et al. Perinatal and maternal outcomes by planned place of birth for healthy women with low risk pregnancies: the Birthplace in England national prospective cohort study. BMJ (Clinical research ed). 2011;343:d7400.

25. Hildingsson IM, Lindgren HE, Haglund B, Radestad IJ. Characteristics of women giving birth at home in Sweden: a national register study. Am J Obstet Gynecol. 2006;195(5):1366-72.

26. Lindgren $\mathrm{H}$, Kjaergaard $\mathrm{H}$, Olafsdottir OA, Blix E. Praxis and guidelines for planned homebirths in the Nordic countries - an overview. Sex Reprod Healthc. 2014;5(1):3-8.

27. Lindgren HE, Brink A, Klinberg-Allvin M. Fear causes tears - perineal injuries in home birth settings. A Swedish interview study. BMC Pregnancy Childbirth. 2011;11:6.

28. Dahlen HG, Dowling H, Tracy M, Schmied V, Tracy S. Maternal and perinatal outcomes amongst low risk women giving birth in water compared to six birth positions on land. A descriptive cross sectional study in a birth centre over 12 years. Midwifery. 2013;29(7):759-64.

29. Cortes E, Basra R, Kelleher CJ. Waterbirth and pelvic floor injury: A retrospective study and postal survey using ICIQ modular long form questionnaires. Eur J Obstet Gynecol Reprod Biol. 2011;155(1):27-30.

30. Smith LA, Price $N$, Simonite $V$, Burns EE. Incidence of and risk factors for perineal trauma: a prospective observational study. BMC Pregnancy Childbirth. 2013;13:59.

31. Shorten A, Donsante J, Shorten B. Birth position, accoucheur, and perineal outcomes: informing women about choices for vaginal birth. Birth (Berkeley, Calif). 2002;29(1):18-27.

32. Soong B, Barnes M. Maternal position at midwife-attended birth and perineal trauma: is there an association? Birth (Berkeley, Calif). 2005;32(3):164-9.

33. Aikins Murphy P, Feinland JB. Perineal outcomes in a home birth setting. Birth (Berkeley, Calif). 1998;25(4):226-34.

34. Gupta JK, Hofmeyr GJ, Shehmar M. Position in the second stage of labour for women without epidural anaesthesia. The Cochrane Database of Systematic Reviews. 2012;5:Cd002006.

35. Naroll F, Naroll R, Howard FH. Position of women in childbirth. A study in data quality control. Am J Obstet Gynecol. 1961;82:943-54.

36. Kemp E, Kingswood CJ, Kibuka M, Thornton JG. Position in the second stage of labour for women with epidural anaesthesia. The Cochrane Database of Systematic Reviews. 2013;1:Cd008070.

37. Blix E, Kumle MH, Ingversen $K$, Huitfeldt AS, Hegaard HK, Olafsdottir OA, Oian P, Lindgren $\mathrm{H}$. Transfers to hospital in planned home birth in four Nordic countries a prospective cohort study. Acta Obstet Gynecol Scand. 2016:95(4):420-8

38. Homer CS, Thornton C, Scarf VL, Ellwood DA, Oats JJ, Foureur MJ, Sibbritt D, McLachlan HL, Forster DA, Dahlen HG. Birthplace in New South Wales. Australia: an analysis of perinatal outcomes using routinely collected data. BMC Pregnancy Childbirth. 2014;14:206.

39. Thiagamoorthy G, Johnson A, Thakar R, Sultan AH. National survey of perineal trauma and its subsequent management in the United Kingdom. Int Urogynecol J. 2014.

40. Baghestan $E$, Irgens LM, Bordahl PE, Rasmussen S. Trends in risk factors for obstetric anal sphincter injuries in Norway. Obstet Gynecol. 2010;116(1):25-34.

41. Stedenfeldt M, Oian P, Gissler M, Blix E, Pirhonen J. Risk factors for obstetric anal sphincter injury after a successful multicentre interventional programme. BJOG. 2014;121(1):83-91.

42. Priddis $\mathrm{H}$, Dahlen $\mathrm{H}$, Schmied $\mathrm{V}$. What are the facilitators, inhibitors, and implications of birth positioning? A review of the literature. Women Birth. 2012;25(3):100-6.

43. De Jonge A, Lagro-Janssen AL. Birthing positions. A qualitative study into the views of women about various birthing positions. J Psychosom Obstet Gynaecol. 2004;25(1):47-55.
44. Downe S. Physiology and care during the transition and second stage phases of labour. In: Fraser DM, Cooper MA, editors. Myles textbook for midwives. Edinburgh: Churchill Livingstone; 2003.

45. How to perform an episiotomy [https://www.rcm.org.uk/news-views-andanalysis/analysis/how-to-perform-an-episiotomy]

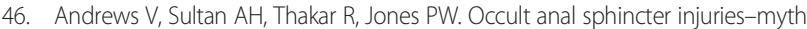
or reality? BJOG. 2006;113(2):195-200.

47. Andrews $\mathrm{V}$, Thakar $\mathrm{R}$, Sultan $\mathrm{AH}$. Structured hands-on training in repair of obstetric anal sphincter injuries (OASIS): an audit of clinical practice. Int Urogynecol J Pelvic Floor Dysfunct. 2009;20(2):193-9.

48. Blix E, Kumle MK, Ingversen K, Huitfeldt AS, Hegaard HK, Ólafsdóttir OÁ, Oian $\mathrm{P}$, Lindgren $\mathrm{H}$. Transfers to hospital in planned home births in four Nordic countries. 2016.

49. Aasheim $V$, Nilsen $A B$, Lukasse M, Reinar LM. Perineal techniques during the second stage of labour for reducing perineal trauma. The Cochrane database of systematic reviews. 2011(12):Cd006672.

\section{Submit your next manuscript to BioMed Central and we will help you at every step:}

- We accept pre-submission inquiries

- Our selector tool helps you to find the most relevant journal

- We provide round the clock customer support

- Convenient online submission

- Thorough peer review

- Inclusion in PubMed and all major indexing services

- Maximum visibility for your research

Submit your manuscript at www.biomedcentral.com/submit
Biomed Central 